\section{Disinfection of contact lenses without tap water rinsing: is it effective?}

\author{
Abstract \\ Purpose To establish the efficacy of the two
} most popular contact lens disinfecting systems - one-step hydrogen peroxide and multipurpose disinfecting solution - for 1 month's use in practice in the absence of tap water rinsing.

Methods This was a descriptive, prospective microbiological study of contact lens contamination with ideal hygiene compliance and new lenses and storage cases. One hundred and fifty contact lens wearers were instructed to avoid risk factors identified for Acanthamoeba infection. They were randomly assigned to use one of three disinfecting systems and taught to follow manufacturers' instructions. In addition, they were taught to avoid all use of tap water for contact lens hygiene, except for hand washing. Results There was no isolation of Acanthamoeba from any lens storage case, precluding the chance of amoebic infection. The multi-purpose solution gave the lowest rate of bacterial contamination, with $78 \%$ sterility and $15 \%$ of cases with $<10^{4}$ bacteria/ml. For both one-step peroxide and multi-purpose solutions, Gram-negative bacteria were reduced in frequency compared with values expected historically, while Bacillus sp. were found more frequently. Storage cases of both one-step peroxide systems leaked fluid.

Conclusions On the basis of contamination in previous studies, when hydrogen peroxide and other chemical disinfectants were used together with tap water washing, it was expected that approximately $40 \%$ of lens storage cases would yield bacteria, often with a high count, and that up to $8 \%$ would yield Acanthamoeba. Such contamination did not occur, however, in this study. The multipurpose solution, for 1 month's use, gave the lowest rate of bacterial contamination with only $7 \%$ of storage cases harbouring bacteria at $>10^{4} / \mathrm{ml}$ and with $78 \%$ sterility. One of the two one-step hydrogen peroxide systems performed equally well. Importantly, Acanthamoeba was not isolated from any of the 150 storage cases. Whether lens storage cases need to be sterile or contain $<1^{3}$ bacteria/ml solution within them is debatable, but it is essential that Acanthamoeba be absent from them.
DAVID V. SEAL, ALAN DALTON, DEREK DORIS

Key words Contact lenses, Disinfection, Acanthamoeba, Tap water, Hydrogen peroxide, Multi-purpose solutions

Recent work in the West of Scotland has established the incidence of microbial keratitis for daily wear of contact lenses as 1:4050 for presumed infection due to all causes and 1:6650 for Acanthamoeba keratitis. ${ }^{1}$ There was a lower rate of contact lens associated keratitis overall compared with a previous prospective cohort study in the USA. ${ }^{2}$ However, there was no statistically significant difference in infection rates between the two studies for the daily wear modality, the majority of cases of keratitis in the American study occurring with extended wear of contact lenses.

Risk factors for Acanthamoeba keratitis were specifically considered when a chain of causation was identified from tap water washing of contact lens storage cases and their contamination with this amoeba. ${ }^{3}$ This study found that patients with Acanthamoeba infection frequently washed their storage cases with tap water, significantly more so than controls, kept their storage cases wet, had a growth of 'coliform' bacteria in the storage case and, finally, had a growth of Acanthamoeba within them. In addition, molecular-based investigations have established domestic tap water as a proven source of Acanthamoeba infection in contact lens wear. ${ }^{4}$

This study was established to investigate whether the two most popular types of contact lens disinfecting systems (one-step hydrogen peroxide and multi-purpose cleaning and disinfecting solution) could work adequately in practice without tap water rinsing of storage cases. It has assessed the microbiological findings in storage cases of contact lens wearers who were instructed to avoid the risk factors established above.

\section{Methods}

One hundred and fifty contact lens wearers took part in this study, from both Glasgow and Newcastle, following the procedure outlined below: 
1. Wearers used a new pair of hydrogel contact lenses (ionic, 55\% water content, FDA group 4), a new storage case and a new bottle of disinfecting fluid (see types below).

2. Tap water was NEVER used to rinse or clean the storage case nor to rinse the contact lenses. Only disinfecting fluid was used in the storage case and home-made solutions were disallowed.

3. Hands were washed before removing contact lenses, and thoroughly dried on a clean, dry hand towel.

4. The contact lenses were cleaned by a 'rub and rinse' technique using the multi-purpose disinfecting solution or hydrogen peroxide as instructed.

5. The contact lenses were placed in the disinfecting solution for overnight storage, and a neutralising tablet was added to the Oxysept hydrogen peroxide system solution.

6. In the morning, the contact lenses were removed from the storage case and placed in the eye. The disinfecting solutions used in this study did not require further neutralisation.

7. The solution was tipped out of the storage case, which was left open to air-dry during the daytime when the lenses were worn. The storage case tops of those using the multi-purpose solution were inverted and the case allowed to air-dry.

8. Contact lenses were worn on a daily wear basis only and removed for swimming.

The contact lens wearer was asked to return the lenses and the storage case, containing the previous night's soaking solution, to the practice after 1 month of use, sealed inside a single-use plastic bag specimen container. It was then stored at $4{ }^{\circ} \mathrm{C}$ prior to culture.
The participants, all of whom had worn contact lenses for at least 6 months, were randomly assigned to use either a multi-purpose solution (Complete (Allergan), containing $1 \mathrm{ppm}$ or $1 \mu \mathrm{g} / \mathrm{ml}$ polyhexamethylene biguanide, $\mathrm{PHMB}$ ) or one of two 'one-step' hydrogen peroxide solutions: Oxysept (Allergan), neutralised by a tablet, or EasySept (Bausch \& Lomb), neutralised by a platinum disc within the storage case.

Storage cases were observed for dirt and turbid contents. The laboratory investigation included microscopy, with culture for bacteria and fungi on a 'chocolate' and MacConkey agar plate incubated at $37^{\circ} \mathrm{C}$ for $48 \mathrm{~h}$ and culture for Acanthamoeba on a non-nutrient agar plate seeded with heat-killed Klebsiella sp. held at $32{ }^{\circ} \mathrm{C}$ for 4 weeks. One millilitre of the storage case solution for hydrogen peroxide containers, and $0.5 \mathrm{ml}$ for each of the two Complete containers (left and right), was flooded over the surface of each plate, except when there was insufficient fluid, when the maximum amount was used. Bacteria were recorded semi-quantitatively as one of three numerical groupings (10 to $10^{2}, 10^{2}$ to $10^{4},>10^{4}$ ), and identified by standard laboratory techniques. Gramnegative bacteria were identified to species level using the API-20E or NE strip identity kit tests. All results were entered on an EXCEL spreadsheet database.

Statistical comparison of the results from the three different disinfecting solutions, for the three categories of sterility, Gram-positive bacteria and Gram-negative bacteria, was performed using the chi-squared test. In addition, the number of storage cases with bacteria at $>10^{4} / \mathrm{ml}$ was compared between Complete, as a representative multi-purpose solution, and the two hydrogen peroxide solutions considered together; results

Table 1. Overall isolation of bacterial species from storage cases exposed to the three disinfecting systems

\begin{tabular}{|c|c|c|c|}
\hline Bacteria isolated from storage cases & $\begin{array}{l}\text { Oxysept } \\
(n=66)\end{array}$ & $\begin{array}{c}\text { EasySept } \\
(n=25)\end{array}$ & $\begin{array}{c}\text { Complete } \\
(n=59)\end{array}$ \\
\hline \multicolumn{4}{|l|}{ Gram-positive flora } \\
\hline Coagulase-negative staphylococci & $2(3 \%)$ & - & • \\
\hline Micrococcus luteus & $\cdot$ & • & $1(2 \%)$ \\
\hline Streptococcus faecalis & $1(2 \%)$ & • & • \\
\hline Bacillus sp. & $8(12 \%)$ & $3(12 \%)$ & - \\
\hline Diphtheroids & $\cdot$ & $2(8 \%)$ & • \\
\hline \multicolumn{4}{|l|}{ Gram-negative flora } \\
\hline Escherichia coli & $1(2 \%)$ & - & $\cdot$ \\
\hline Klebsiella sp. & $\cdot$ & - & $1(2 \%)$ \\
\hline Serratia liquefaciens sp. & $3(5 \%)$ & • & $1(2 \%)$ \\
\hline Enterobacter sakazakii & $2(3 \%)$ & $1(4 \%)$ & $1(2 \%)$ \\
\hline Coliform (LF) & $\cdot$ & 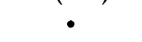 & $1(2 \%)$ \\
\hline Coliform (NLF) - environmental & $1(2 \%)$ & - & $\cdot$ \\
\hline Pseudomonas fluorescens & $2(3 \%)$ & - & - \\
\hline \multicolumn{4}{|l|}{ Polymicrobial flora } \\
\hline Bacillus sp./CNS/micrococcus/diphtheroids & . & - & $1(2 \%)$ \\
\hline CNS/micrococcus/diphtheroids & $6(9 \%)$ & - & $3(5 \%)$ \\
\hline Bacillus sp. + CNS & $4 \quad(6 \%)$ & - & $3(5 \%)$ \\
\hline Bacillus sp. + Enterobacter sakazakii & $2(3 \%)$ & $\cdot$ & $\cdot$ \\
\hline Bacillus sp. + Serratia liquefaciens & $\cdot$ & $1(4 \%)$ & - \\
\hline \multirow{2}{*}{ CNS + Escherichia coli + Serratia liquefaciens + Pseudomonas fluorescens } & $1(2 \%)$ & $\cdot$ & - \\
\hline & $\cdot$ & $1(4 \%)$ & - \\
\hline Coliform $(\mathrm{LF})+$ mixed coliform $(\mathrm{NLF})$ & $1(2 \%)$ & $\cdot$ & - \\
\hline
\end{tabular}

LF, lactose fermenting; NLF, non-lactose fermenting; CNS, coagulase-negative staphylococci; ( ), approximate percentage; ' $\bullet$ ', not isolated. 


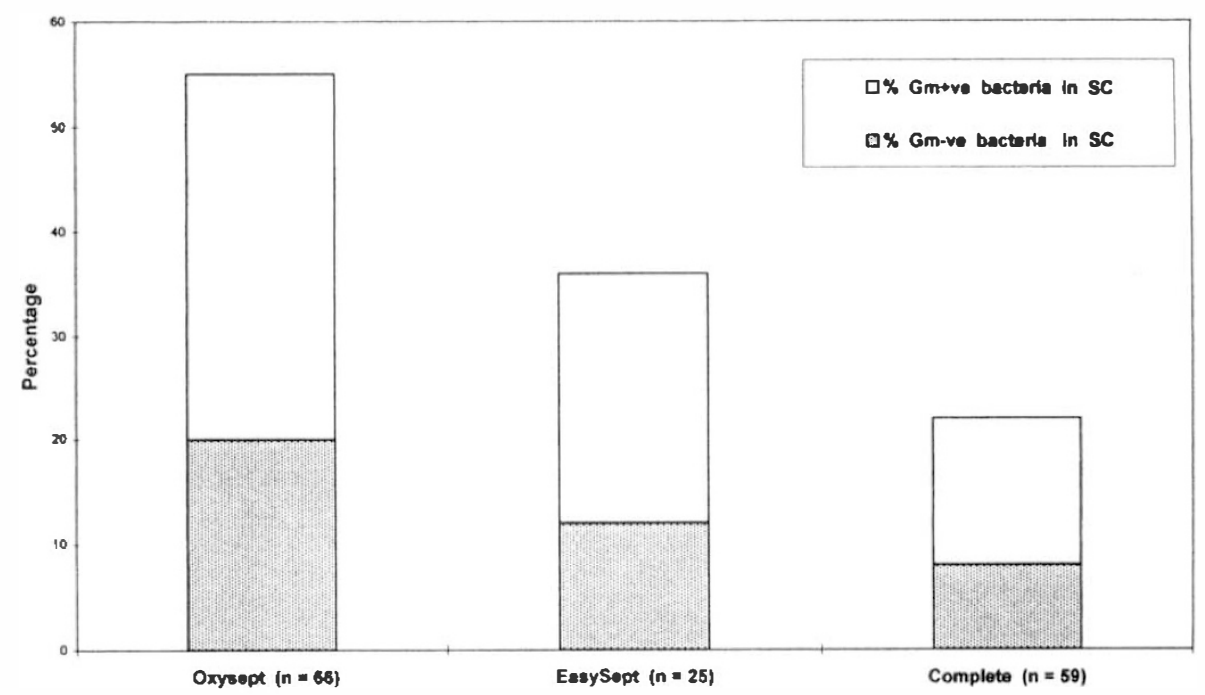

Fig. 1. Overall percentage isolation of bacteria from storage cases (SC).

were analysed using the chi-squared test. As Acanthamoeba was not isolated, there was no statistical test to apply.

\section{Results}

The presence of more than 10 colonies on the agar plate was considered significant and the colonies were identified and recorded. Values ranged from 10 (approximately $>10 / \mathrm{ml}$ ) to confluence on the plate (approximately $>10^{4} / \mathrm{ml}$ ). There were instances of both single and mixed bacterial contamination. Overall isolation of each bacterial species from the storage cases is given in Table 1. It should be noted that Staphylococcus aureus and Pseudomonas aeruginosa were never isolated.

Results for the overall percentage isolation of Grampositive bacteria and Gram-negative (including 'coliform' and environmental) bacteria are given in Fig. 1 and Table 2 for the three disinfecting solutions used. Statistical evaluation comparing Complete and EasySept with Oxysept is given in Table 3; there was no statistical difference found between Complete and EasySept.

For comparison of Complete, as a representative multi-purpose solution, and the two one-step hydrogen peroxide systems, there were 4 of 59 storage cases with bacterial counts at $>10^{4} / \mathrm{ml}$ for Complete and 30 of 91 storage cases with bacterial counts at $>10^{4} / \mathrm{ml}$ for the peroxide systems (25/66 for Oxysept and 5/25 for EasySept). The chi-squared value for the difference between them is $14.003(p<0.001)$.

Table 2. Overall percentage isolation of storage case bacteria with three disinfecting systems

\begin{tabular}{lcccc}
\hline Disinfectant & $\begin{array}{c}\text { No. in } \\
\text { trial }\end{array}$ & $\begin{array}{c}\text { \% Gram- } \\
\text { positive }\end{array}$ & $\begin{array}{c}\text { \% Gram- } \\
\text { negative }\end{array}$ & \% sterile \\
\hline Oxysept $\left(\mathrm{H}_{2} \mathrm{O}_{2}\right)$ & 66 & 35 & 20 & 48 \\
EasySept $\left(\mathrm{H}_{2} \mathrm{O}_{2}\right)$ & 25 & 24 & 12 & 68 \\
Complete (MP) & 59 & 14 & 8 & 78 \\
\hline
\end{tabular}

$\mathrm{H}_{2} \mathrm{O}_{2}$, hydrogen peroxide; MP, multi-purpose.
Acanthamoeba was not isolated from any storage case in this study, despite prolonged culture. The growth conditions were quality controlled and control cultures of Acanthamoeba were able to be isolated satisfactorily on the agar used during the period of this study.

\section{Discussion}

This study was designed to assess the effectiveness of the new contact lens disinfecting systems - 'one-step' hydrogen peroxide and a typical multi-purpose solution - in an ideal hygiene compliance situation, avoiding the recognised risk factors for Acanthamoeba contamination. With knowledge of identifiable risk factors for Acanthamoeba keratitis from the Scottish study, ${ }^{3}$ an ideal hygiene procedure was defined which included:

(1) changing the contact lenses and storage case on a monthly basis, at the same time; (2) avoiding any use of tap water in the hygiene regimen, excepting for hand washing; and (3) air-drying of the storage case when the lenses were worn. The study protocol has been defined above.

Cleaning of contact lenses after daily wear was practised by a 'rub and rinse' technique. The two hydrogen peroxide systems were not supplied with a separate, detergent-based cleaning solution and the lenses were therefore 'rubbed and rinsed' with neat hydrogen peroxide from the bottle. This may have influenced microbial contamination of the storage case, as the effectiveness of poloxomer-containing cleaning

Table 3. Statistical comparison of the different disinfecting systems

\begin{tabular}{lccc}
\hline Versus & \multicolumn{3}{c}{ Oxysept } \\
\cline { 2 - 4 } & Sterile & $\begin{array}{c}\text { Gram-positive } \\
\text { bacteria }\end{array}$ & $\begin{array}{c}\text { Gram-negative } \\
\text { bacteria }\end{array}$ \\
\hline Complete & $p<0.001$ & $p<0.01$ & $p<0.1$ \\
& $\left(\chi^{2}=11.5\right)$ & $\left(\chi^{2}=7.6\right)$ & $\left(\chi^{2}=3.2\right)$ \\
EasySept & $p<0.1$ & NS & NS \\
& $\left(\chi^{2}=2.8\right)$ & & \\
\hline
\end{tabular}


agents has been demonstrated for the removal of adsorbed Acanthamoebae. ${ }^{5,6}$ Their effectiveness for removing protein deposits has been criticised, however, as at least $50 \%$ of the deposits were found to remain after cleaning. ${ }^{7}$

Our most important finding has been a total absence of Acanthamoeba from the 150 storage cases cultured in this study. In 1990 in Bristol a 7\% rate of Acanthamoeba contamination of storage cases was found, ${ }^{8}$ when there was an associated bacterial count for 6 of 7 storage cases at $>10^{6} / \mathrm{ml}$. In 1993 in the West of Scotland a rate of $4 \%$ Acanthamoeba contamination was found, ${ }^{9}$ all in users of tablet-based chlorine solutions; in this subgroup the rate of Acanthamoeba contamination was 7 of 54 (13\%) storage cases. In 1995 in New Zealand an 8\% rate of Acanthamoeba contamination of storage cases occurred with the use of hydrogen peroxide (mostly one-step solutions) or multi-purpose solutions; ${ }^{10}$ however, this study also found Naegleria sp., flagellates and ciliates in the storage cases, which demonstrated the presence of tap water use in the hygiene regimen. All these studies have found combined contamination of bacteria and Acanthamoeba within the storage case.

This study has identified that avoiding tap water use also avoids contamination with Acanthamoeba. The New Zealand study ${ }^{10}$ has shown that one-step hydrogen peroxide solutions in particular can readily be contaminated with Acanthamoeba from adjunctive tap water use. The authors found that all their contaminating bacteria produced catalase, which breaks down hydrogen peroxide to oxygen and water. This illustrates the ineffectiveness of one-step hydrogen peroxide for disinfection of contaminated storage cases, which is exacerbated by the rapid inactivation of the peroxide after approximately $10 \mathrm{~min}$ in the 'one-step' products.

This study has specifically identified the type of bacterial contamination that occurs in lens storage cases which have not been rinsed in tap water. The multipurpose solution, Complete, gave statistically significant better results against one of the two 'one-step' peroxide solutions (Oxysept), but there was no significant difference compared with the other one (EasySept). These results may be related to the ease with which the Oxysept container leaked through the three holes in its lid, although the EasySept container also leaked from around the junction between the lid and the base. The storage cases supplied for the use with Complete, with twin compartments for the left and right lenses, did not leak at all.

An interestingly high count of Gram-positive bacteria was found with all three solutions, with Bacillus sp. in particular contaminating the hydrogen peroxide systems. Clearly this aerobic spore-bearing bacterium can contaminate the storage case equipment when exposed in the domestic bathroom and produce spores that are resistant to the approximately $10 \mathrm{~min}$ exposure time to hydrogen peroxide; the exposure time can be further reduced if other catalase-producing bacteria are present. The presence of coagulase-negative staphylococci, micrococci and diphtheroids within the storage cases demonstrates how the lid margin bacteria are carried from the ocular surface into the storage case attached to the contact lens surface.

The Gram-negative bacteria identified, in particular Serratia liquefaciens, Enterobacter sakazakii and Pseudomonas fluorescens, were representative of environmental bacterial flora, such as might be found on a face flannel, rather than being derived from faecal coliform flora. Isolates such as Escherichia coli and Streptococcus faecalis may have been derived from finger contamination of eye lids, and the contact lens, but they can be found as well in the damp environment of items such as face flannels. Pseudomonas aeruginosa was not isolated from any one of 150 storage cases used in this study. It is, however, known that extended-wear contact lenses can become contaminated with $P$. aeruginosa without the use of storage cases, ${ }^{11}$ while the route of contamination from the ocular surface to the storage case may be responsible more often than the other way around. $P$. aeruginosa is rarely found in storage cases of contact lens wearers without keratitis. It was present in only 2 of 132 (1.5\%) storage cases in the previous Scottish study of storage case microbiology in the community. ${ }^{9}$

Much higher bacterial and Acanthamoeba counts have been observed in storage cases in previous studies by others. In Bristol in $1990,{ }^{8}$ there was a $42 \%$ contamination rate with bacterial counts $>10^{6} / \mathrm{ml}$ when contact lens wearers disinfected their storage cases with chlorhexidine (at a low concentration), chlorine and hydrogen peroxide (two-step procedure). In the previous Scottish study ${ }^{9}$ there was a $53 \%$ rate of bacterial contamination of storage cases but quantitative counts were not performed; a mixture of hydrogen peroxide (two-step procedure), chemical and chlorine disinfectants were used by contact lens wearers for which a relative risk of contamination was calculated of 1.0 for peroxide, 1.6 for chemicals and 2.22 for chlorine. This was not the situation, however, in the most recent study from New Zealand, ${ }^{10}$ when there was a $53 \%$ contamination rate for bacteria (counts not performed) and $8 \%$ for Acanthamoeba; $70 \%$ of these lens wearers used one-step hydrogen peroxide solutions, which were associated with more contamination $(p<0.05)$ than the non-peroxide disinfecting systems probably because of frequent tap water use.

The presence of bacterial contamination in storage cases at $>10^{4} / \mathrm{ml}$ has been found more frequently in this study $(p<0.001)$ with the one-step hydrogen peroxide systems than with the mutli-purpose solution. An explanation for this finding is that the one-step peroxide systems are rapidly inactivated with no residual disinfecting effect, producing contaminated water in which the microbes can multiply easily. This is not the case for multi-purpose solutions containing polyhexamethylene biguanide (PHMB), such as Complete at $0.0001 \%$, which retain a residual disinfecting effect at all times except when there is gross bacterial contamination. The chances of contamination are reduced by monthly changing of storage cases and avoiding use of tap water. Our lowest rate for 
contamination was $22 \%$, or $7 \%$ for a bacterial count at $>10^{4} / \mathrm{ml}$, which occurred with the multi-purpose solution Complete.

The bacterial count that may arise within a contact lens storage case is of particular interest. Firstly, a high count is more likely to inactivate hydrogen peroxide due to the production of catalase by the bacteria. Secondly, a high count of at least $10^{6} / \mathrm{ml}$, but more often of $10^{7} / \mathrm{ml}$, is required for bacteria to produce a biofilm. ${ }^{12-14}$ This will coat the contact lens surface within $24 \mathrm{~h}$ and then allows any Acanthamoeba present to adsorb in higher numbers to the lens. ${ }^{12,13}$ Biofilm is produced particularly by

Pseudomonas spp., so that protection from contamination with these organisms in high numbers may also protect against an increased risk for Acanthamoeba keratitis. However, the need for sterility within the storage case is debatable. A low bacterial count $\left(<10^{3} / \mathrm{ml}\right)$ in the absence of Acanthamoeba, such as was found in this study with the use of the multipurpose disinfecting solution, together with monthly changes of lens and storage case simultaneously and avoidance of tap water, provides the soft contact lens wearer with conditions that should preclude the chance of infection occurring. It will also prevent the build-up of biofilm and microbial contamination within the storage case, which predisposes the contact lens wearer to microbial keratitis from a large inoculum of bacteria or amoebae adherent to the contact lens after it has been immersed in the contaminated contents.

We are very grateful to all the staff of the Eye Clinic in Glasgow and Newcastle for their enthusiastic help with this study. We are also grateful to Mr Derek Black and the Western Infirmary microbiology department for their invaluable assistance.

\section{References}

1. Seal DV, Kirkness CM, Bennett HB, Peterson M. Populationbased cohort study of microbial keratitis in Scotland: incidence and features. Contact Lens \& Anterior Eye; in press.

2. Poggio EC, Glynn RJ, Schein OD, Seddon JM, Shannon MJ, Scardino VA, Kenyon KR. The incidence of ulcerative keratitis among users of daily-wear and extended-wear soft contact lenses. N Engl J Med 1989;321:779-83.

3. Seal DV, Kirkness CM, Bennett HB, Peterson M. Acanthamoeba keratitis in Scotland: risk factors for contact lens wearers. Contact Lens \& Anterior Eye; in press.

4. Ledee DR, Hay J, Byers TJ, Seal DV, Kirkness CM. Acanthamoeba griffini: molecular characterisation of a new corneal pathogen. Invest Ophthalmol Vis Sci 1996;37:544-50.

5. Kilvington S, Larkin DFP. Acanthamoeba adherence to contact lenses and removal by cleaning agents. Eye 1990;4:590-3.

6. Kilvington S. Acanthamoeba trophozoite and cyst adherence to four types of soft contact lens and removal by cleaning agents. Eye 1993;7:535-8.

7. Jung J, Rapp J. The efficacy of hydrophilic contact lens cleaning systems in removing protein deposits. CLAO J 1993;19:47-50.

8. Larkin DFP, Kilvington S, Easty DL. Contamination of contact lens storage cases by Acanthamoeba and bacteria. Br J Ophthalmol 1990;74:133-5.

9. Devonshire P, Munro FA, Abernethy C, Clark BJ. Microbial contamination of contact lens storage cases in the West of Scotland. Br J Ophthalmol 1993;77:41-5.

10. Gray TB, Cursons TM, Sherwan JF, Rose PR. Acanthamoeba, bacterial and fungal contamination of contact lens storage cases. Br J Ophthalmol 1995;79:601-5.

11. Stapleton F, Dart J, Seal DV, Matheson M. Epidemiology of Pseudomonas aeruginosa keratitis in contact lens wearers. Epidemiol Infect 1995;114:395-42.

12. Gorlin AIO, Gabriel MM, Wilson LA, Ahearn DG. Effect of adhered bacteria on the binding of Acanthamoeba to hydrogel lenses. Arch Ophthalmol 1996;114:576-80.

13. Simmons P, Tomlinson A, Seal DV. Acanthamoeba adsorption to 4 types of hydrogel lenses previously coated with $P$ s. aeruginosa biofilm. Optom Vis Sci 1998;75:860-6.

14. Slusher MM, Myrvik QN, Lewis JC, Gristina AG. Extended wear lenses, biofilm and bacterial adhesion. Arch Ophthalmol 1987;105:110-5. 